\title{
Review: lifestyle or pharmacological interventions prevent or delay type 2 diabetes in people with impaired glucose tolerance
}

Gillies CL, Abrams KR, Lambert PC, et al. Pharmacological and lifestyle interventions to prevent or delay type 2 diabetes in people with impaired glucose tolerance: systematic review and meta-analysis. BMJ 2007;334:299.

\section{$Q$ In people with impaired glucose tolerance, do lifestyle or pharmacological interventions prevent or delay type 2 diabetes?}

\section{METHODS}

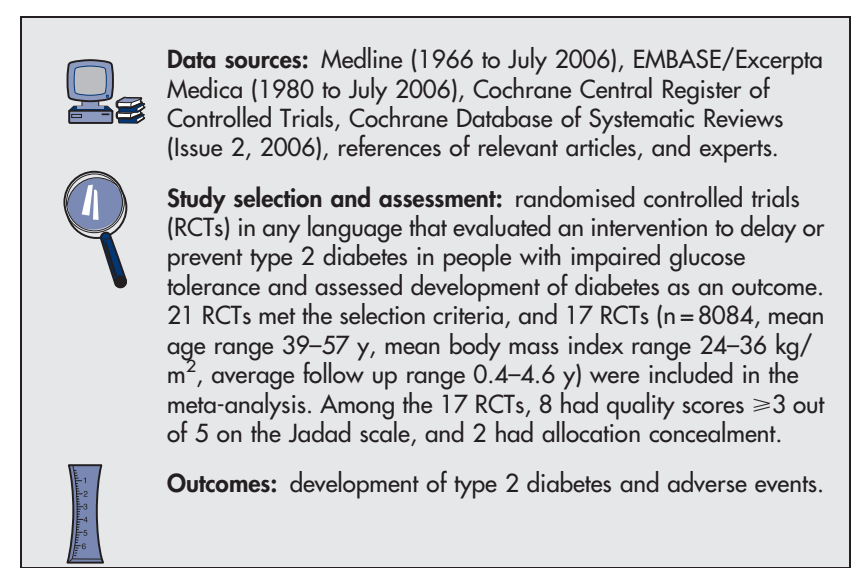

\section{MAIN RESULTS}

Meta-analysis using a random effects model showed that both lifestyle interventions (diet, exercise, or both) and pharmacological interventions (oral diabetes drugs [acarbose, flumamine, glipizide, metformin, or phenformin] or an anti-obesity drug [orlistat]) reduced the incidence of type 2 diabetes (table); 2 trials assessing troglitazone were excluded from the meta-analysis because the drug had been removed from several markets worldwide because of liver toxicity. In 1 trial, jiangtang bushen (a Chinese herbal) did not reduce diabetes (table). Adverse events related to pharmacological interventions (gastrointestinal and hypoglycaemic symptoms) were more common in the treatment groups (no statistical tests reported).

\section{CONCLUSION}

In people with impaired glucose tolerance, lifestyle or pharmacological interventions prevent or delay type 2 diabetes.

For correspondence: Ms C L Gillies, University of Leicester, Leicester, UK. clg13@le.ac.uk

Sources of funding: UK Medical Research Council and Economic and Social Research Council.
A modified version of this abstract appears in ACP Journal Club.

\section{Commentary}

he natural history of type 2 diabetes includes a period of impaired glucose tolerance before a diagnosis of diabetes is made. The cornerstone for treating type 2 diabetes is lifestyle and/or pharmacological interventions. ${ }^{12}$ The meta-analysis by Gillies et al adds good evidence that lifestyle and pharmacological interventions may also prevent or delay the onset of type 2 diabetes. Although some clinicians may prefer reports of other outcomes variables (eg, glucose or glycated haemoglobin concentrations), Gillies et al were limited in their reporting to the data presented in the primary studies.

Strategies for successful lifestyle interventions include individualised, tailored, long term interactions with a facilitator; dietary and physical activity goal setting; and behaviour modification. ${ }^{3}$ Strategies for successful medication adherence in pharmacological interventions may include frequent nurse-patient communications and understanding the strengths and weaknesses of the patient's social context. Cost effectiveness of interventions, from both short term and lifetime perspectives, needs further examination. ${ }^{3}$ Of interest, a follow up to the Finnish Diabetes Prevention Study revealed that sustained lifestyle changes and reductions in diabetes incidence continued to occur even after the intervention stopped. ${ }^{4}$ Lifestyle changes seem to be at least as effective as drugs for preventing type 2 diabetes. Healthcare workers should support such changes (smoking cessation, healthy eating, increased physical activity, and some weight loss) at every opportunity.

Sandra L Upchurch, RN, PhD University of Texas Health Science Center at Houston School of Nursing Houston, Texas, USA

1 Bethel MA, Califf RM. Role of lifestyle and oral anti-diabetic agents to prevent type 2 diabetes mellitus and cardiovascular disease. Am J Cardio 2007:99:726-31.

2 Yamaoka K, Tango T. Efficacy of lifestyle education to prevent type 2 diabetes: a meta-analysis of randomized controlled trials. Diabetes Care 2005;28:2780-6.

3 Wylie-Rosett J, Herman WH, Goldberg RB. Lifestyle intervention to prevent diabetes: intensive and cost effective. Curr Opin Lipidol 2006;17:37-44.

4 Lindström J, llanne-Parikka P, Peltonen M, et al. Sustained reduction in the incidence of type 2 diabetes by lifestyle intervention: follow-up of the Finnish Diabetes Prevention Study. Lancet 2006;368:1673-9.

Lifestyle or pharmacological interventions $v$ placebo to prevent or delay type 2 diabetes in people with impaired glucose tolerance*

\begin{tabular}{llllc}
\hline Outcome at mean 0.4-4.6 y & Comparisons & Number of trials $(\mathbf{n})$ & Hazard ratio $(\mathbf{9 5 \%}$ Cl) & NNT (credible interval) \\
\hline Type 2 diabetes & Lifestyle $v$ placebot & $10(4452)$ & $0.51(0.44$ to 0.60$)$ & $7(5$ to 9$)$ \\
& Oral diabetes drug v placebo $\neq$ & $8(4580)$ & $0.70(0.62$ to 0.79$)$ & $11(9$ to 15$)$ \\
& Orlistat $v$ placebo & $2(814)$ & $0.44(0.28$ to 0.69$)$ & $6(5$ to 8$)$ \\
& Jiangtang bushen $v$ placebo & $1(51)$ & $0.32(0.03$ to 3.07$)$ & Not significant \\
\hline
\end{tabular}

*Abbreviations defined in glossary.

thifestyle interventions included diet, exercise, or both.

†Oral diabetes drugs were acarbose, flumamine, glipizide, metformin, or phenformin. 